\title{
Prognostic significance of FOXL2 mutation and mRNA expression in adult and juvenile granulosa cell tumors of the ovary
}

\author{
Emanuela D’Angelo*, Ana Mozos*, Daiei Nakayama, Iñigo Espinosa, Lluis Catasus, \\ Josefina Muñoz and Jaime Prat \\ Department of Pathology, IIB-Sant Pau, Hospital de la Santa Creu i Sant Pau, Autonomous University of \\ Barcelona, Barcelona, Spain
}

\begin{abstract}
Recently, mutation of the FOXL2 gene has been consistently identified in adult granulosa cell tumors of the ovary. The purpose of this study is to investigate whether the FOXL2 mutation and mRNA expression have a role in the pathogenesis of juvenile and adult granulosa cell tumors and influence tumor progression. Thirty-four adult granulosa cell tumors and 20 juvenile granulosa cell tumors were examined for the presence of the FOXL2 (C402G) mutation. Expression levels were studied by quantitative PCR and immunohistochemistry. We found that FOXL2 (C402G) mutation was present in 19/27 (70\%) of the adult type tumors but in none of the juvenile granulosa cell tumors (0/18). No correlation was encountered between the presence of FOXL2 mutation and various clinicopathologic parameters except for the presence of a different sex-cord component, which was more frequently found in the subgroup of wild-type adult granulosa cell tumors than in the mutated tumors. Patients with tumors harboring the FOXL2 (C402G) mutation had a worse disease-free survival than those with the wild-type gene. Expression levels of FOXL2 mRNA had an impact on disease-free survival in both adult and juvenile granulosa cell tumors. We also found that the mutated tumors had a higher immunohistochemical expression of the FOXL2 protein, and there was a linear correlation between mRNA and immunohistochemical FOXL2 expression in both adult and juvenile granulosa cell tumors. Patients with juvenile granulosa cell tumors and higher FOXL2 protein expression had worse overall survival and disease-free survival than those with negative or weakly immunoreactive tumors. Our data suggest that FOXL2 mutation and mRNA expression are of prognostic importance in both adult and juvenile granulosa cell tumors.

Modern Pathology (2011) 24, 1360-1367; doi:10.1038/modpathol.2011.95; published online 27 May 2011
\end{abstract}

Keywords: adult granulosa cell tumors; FOXL2 mRNA; juvenile granulosa cell tumors; ovary; survival

Granulosa cell tumors are the prototype of feminizing sex cord-stromal tumors and represent around $3-5 \%$ of all ovarian tumors. ${ }^{1}$ They comprise two different types, adult and juvenile, that account for 95 and $5 \%$, respectively. The adult form occurs more often in middle-aged women and may show a variety of patterns including macrofollicular, microfollicular (the most characteristic), insular, or trabecular. Neoplastic cells are uniform with scanty

Correspondence: Professor J Prat, MD, FRCPath, Department of Pathology, IIB-Sant Pau, Santa Creu i Sant Pau Hospital, Autonomous University of Barcelona, 87-89 S. Quintin, Barcelona 08041, Spain.

E-mail: jprat@santpau.cat

*These authors contributed equally to this work.

Received 21 February 2011; revised 1 April 2011; accepted 1 April 2011; published online 27 May 2011 cytoplasm and pale, grooved nuclei; in contrast, the juvenile subtype occurs mainly in children and younger women and usually shows large rudimentary follicles and cells with moderate to abundant cytoplasm and darker nuclei often without grooves. $^{1,2}$ In both types, stage at the time of diagnosis is thought to be the most powerful factor predicting outcome..$^{3-8}$ Whereas the adult type requires long-term follow-up due to its tendency to late recurrences, juvenile granulosa cell tumors tend to be confined to the ovary and are associated with favorable prognosis. Only juvenile tumors extending beyond the ovary are associated with poor outcome. ${ }^{6,7,9}$

Somatic mutation in the FOXL2 gene has been described as a potential 'driver' in the pathogenesis of adult granulosa cell tumors. ${ }^{10}$ FOXL2 is an evolutionarily conserved single-exon gene of $2.7 \mathrm{~kb}$ 
located at 3q23 that encodes for a 376 aa protein belonging to the large family of forkhead transcription factors. ${ }^{11}$ FOXL2 expression is restricted to granulosa cells during development and adulthood. ${ }^{12}$ FOXL2 overexpression induces apoptosis in ovarian granulosa cells, whereas its alteration induces premature ovarian failure due to the abnormal granulosa cell differentiation. ${ }^{13-15}$ The missense point mutation (C402G) induces an amino-acid change in FOXL2 (C134W) but neither altered function nor mislocalization of the protein have been reported. ${ }^{10}$ Previous studies have shown that this mutation is specific for the adult type granulosa cell tumors and is present in up to 95-97\% of these tumors. ${ }^{10,16}$ Recently, mutant FOXL2 has been found to induce lower levels of apoptosis compared with wild-type FOXL2. ${ }^{17}$

The purpose of this investigation was to find out whether FOXL2 mutation and expression levels have a role in the pathogenesis of juvenile and adult granulosa cell tumors as well as its potential value as a prognostic factor.

\section{Materials and methods}

\section{Case Selection}

Fifty-four ovarian granulosa cell tumors diagnosed from 1984 to 2009 were retrieved from the Surgical Pathology database of the Hospital de la Santa Creu i Sant Pau, Barcelona (eight cases) and the consultation files of one of the authors (JP, 46 cases). The cases included 34 adult granulosa cell tumors and 20 juvenile granulosa cell tumors. All available slides were reviewed by two of the pathologist (EDA and JP). Clinical and pathologic information regarding patient's age, clinical symptoms, tumor size, gross features, stage, treatment, and follow-up were recorded from the hospital charts and pathology reports.

Tumors were staged by the criteria proposed by the International Federation of Gynecology and Obstetrics (FIGO). A stage was assigned retrospectively on the basis of the recorded intraoperative and pathologic findings if it had not been assigned initially or the results of the initial staging were unavailable. Recurrent tumor was defined as tumor found at an interval after the apparently complete removal of an adequately staged tumor.

Microscopically, the tumors were classified according to the 2003 WHO classification system. ${ }^{1}$ Tumors exhibiting microfollicles composed of uniform cells with scanty cytoplasm and pale grooved nuclei were diagnosed as adult granulosa cell tumors with microfollicular pattern (Call-Exner bodies); others include the trabecular, diffuse (sarcomatoid), and watered silk patterns. In contrast, the juvenile subtype typically shows large rudimentary follicles formed by cells with moderate to abundant cytoplasm and darker nuclei usually without grooves. Mitotic activity was assessed by counting mitotic figures in $10 \mathrm{HPFs}(\mathrm{HPF}=$ $0.196 \mathrm{~mm}^{2}$ ) in the most cellular areas.

\section{Tissue Microarray}

Paraffin blocks were available in all 54 ovarian granulosa cell tumors. Areas showing tumor elements were selected on H\&E slides and marked on the corresponding paraffin blocks. Two representative $0.6 \mathrm{~mm}$ tissue cores were obtained from each selected zone. Tissue cores were arrayed in a paraffin block using a tissue microarray workstation (Beecher Instruments, Silver Spring, MD, USA) as previously described. ${ }^{18}$ An H\&E-stained section was made to confirm the presence of the original areas selected from each tumor. Subsequently, serialsectioned slides were obtained.

\section{Immunohistochemistry}

Immunohistochemical staining of the tissue microarray was performed with primary polyclonal antibody against FOXL2 (1:100; Imgenex, San Diego, CA, USA). Normal ovarian tissue sample was used as positive control. Negative control was produced by omission of the primary antibody. Cases were evaluated by two pathologists (EDA and AM). A case was considered negative when no nuclear immunoreaction was observed, whereas a positive case showed nuclear immunostaining, which was classified in three grades according to the intensity of immunostaining ( 1 for weak, 2 for moderate, and 3 for strong immunoreaction).

\section{FOXL2 Mutational Analysis}

Genomic DNA was isolated from paraffin-embedded tissue blocks using the QIAamp DNA FFPE Tissue Kit (Qiagen, Valencia, CA, USA) according to the manufacturer's instructions. FOXL2 gene was amplified using a semi-nested technique, as previously described. The first pair of oligonucleotides consisted in a forward primer (F1), $5^{\prime}$-CCAGTACATCAT CGCGAAGTTCCCG-3'; and reverse primer (R), $5^{\prime}$-CT CCGGCCCCGAAGAGCC- $3^{\prime}$. The thermal cycling conditions included an initial $12 \mathrm{~min}$ at $94^{\circ} \mathrm{C}$ followed by 35 cycles of $45 \mathrm{~s}$ at $94^{\circ} \mathrm{C} 45 \mathrm{~s}$ at specific annealing primer temperature of $50^{\circ} \mathrm{C} 1 \mathrm{~min}$ at $72^{\circ} \mathrm{C}$ and a final extension of $10 \mathrm{~min}$ at $72^{\circ} \mathrm{C}$. All PCR products (269 bp) were subsequently used as a template in a second PCR, using the same reverse primer (R) and a nested forward primer (F2), 5'-CAG CCTCAACGAGTGCTTCAT- $3^{\prime}$, with a specific annealing primer temperature of $57^{\circ} \mathrm{C}$. The resulting fragment of $194 \mathrm{bp}$ contained the codon 134 . The PCR products were purified using the exoSAP-IT (USB, Affimetrix, Cleveland, OH, USA) and subjected to direct sequencing using the ABI PRISM big Dye terminator v1.1 cycle sequencing Kit 
(Applied Biosystems, Foster City, CA, USA). Sequencing fragments were detected by capillary electrophoresis using an automated ABI PRISM 310 Genetic Analyzer (Applied Biosystems).

\section{FOXL2 Gene Expression}

The mRNA levels of FOXL2 were evaluated by quantitative PCR. Total RNA was extracted using the RNeasy FFPE Kit (Qiagen) and following the manufacturer's instructions. cDNA was synthesized from $1 \mu \mathrm{g}$ of total RNA using the HighCapacity cDNA Reverse Transcription kit (Applied Biosystems). Subsequently, products were amplified with the 7300 Real-Time PCR System (Applied Biosystems) and TaqMan gene expression assay (Hs00846401_s1; Applied Biosystems). The thermal cycling condition were $2 \mathrm{~min}$ at $50^{\circ} \mathrm{C}$ and $10 \mathrm{~min}$ at $95^{\circ} \mathrm{C}$, followed by 40 cycles of $15 \mathrm{~s}$ at $95^{\circ} \mathrm{C}$ and $1 \mathrm{~min}$ at $60^{\circ} \mathrm{C}$. The experiments were performed in triplicate. Normal ovarian pool tissue was used as a calibrator for quantitative Real-Time PCR, and ABL-1 housekeeping gene (Hs01104728_m1; Applied Biosystems) was the reference for normalization.

\section{Statistical Analysis}

Statistical analysis was performed using the SPSS v18 statistical software (SPSS, Chicago, IL, USA). The following clinicopathologic parameters were evaluated: age, tumor size, histologic type, presence of a different sex-cord component, clinicopathologic stage, FOXL2 mutation, gene expression, and patients' outcome. Non-parametric tests (KruskalWallis and Mann-Whitney tests) were used to compare the distribution of quantitative variables. Disease-free survival, defined as the time from the date of diagnosis until the date of disease progression, was calculated according to the Kaplan-Meier method. Actuarial disease-free survival rates were compared using Cox-Mantel and log rank test. Welch two-sample $t$-test was used to investigate the relationship between prognostic parameters and disease-free survival. The significance level was established at 0.05 .

\section{Results}

\section{Clinical and Operative Findings}

The clinicopathologic features are summarized in Table 1. Patients with adult granulosa cell tumors had a median age of 51 (interquartile range $(I Q R)=36-69)$ at the time of diagnosis. In contrast, patients with juvenile granulosa cell tumors had a median age of 36 (IQR $=18-39$ ) at the time of diagnosis. For women in the reproductive age group, initial manifestations included irregular and excessive uterine bleeding; similarly, the most common symptom in postmenopausal women, was vaginal
Table 1 Clinicopathologic features of granulosa cell tumors

\begin{tabular}{|c|c|c|}
\hline & Adult & Juvenile \\
\hline Total (cases) & 34 & 20 \\
\hline Age (years) & $51(36-69)^{\mathrm{a}}$ & $36(18-39)^{a}$ \\
\hline Size $(\mathrm{cm})$ & $11(6-17)^{\mathrm{a}}$ & $18(12-25)^{\mathrm{a}}$ \\
\hline \multicolumn{3}{|l|}{ Histology } \\
\hline Diffuse & $21(62 \%)$ & \\
\hline Trabecular & $6(17 \%)$ & \\
\hline Microfollicular & $4(12 \%)$ & \\
\hline Watered silk & $3(9 \%)$ & \\
\hline Mitoses (MF/10 HPF) & $5(4-14)^{\mathrm{a}}$ & $12(6-21)^{\mathrm{a}}$ \\
\hline \multicolumn{3}{|l|}{ Stage } \\
\hline IA & $31 / 34(91 \%)$ & $15 / 20(75 \%)$ \\
\hline IC & $3 / 34(9 \%)$ & $2 / 20(10 \%)$ \\
\hline IIIB & & $1 / 20(5 \%)$ \\
\hline IIIC & & $2 / 20(10 \%)$ \\
\hline \multicolumn{3}{|l|}{ Treatment } \\
\hline SO & $21(62 \%)$ & $14(70 \%)$ \\
\hline BSO & $10(29 \%)$ & $6(30 \%)$ \\
\hline TAH-BSO & $3(9 \%)$ & \\
\hline Recurrences & $12 / 29(41 \%)$ & $3 / 13(23 \%)$ \\
\hline \multicolumn{3}{|l|}{ Outcome } \\
\hline NED & $16 / 29(56 \%)$ & $10 / 13(77 \%)$ \\
\hline DOD & 0 & $3 / 13(23 \%)$ \\
\hline DOC & $1 / 29(3 \%)$ & 0 \\
\hline
\end{tabular}

BSO, bilateral salpingo-oophorectomy; DOC, dead of unrelated causes; DOD, dead of disease; NED, no evidence of disease; SO, salpingo-oophorectomy; TAH, total abdominal hysterectomy.

${ }^{\mathrm{a}}$ Values are shown as median (interquartile range).

bleeding. The initial treatment was known in all cases: of the 34 patients with adult granulosa cell tumors, $3(9 \%)$ underwent total abdominal hysterectomy with bilateral salpingo-oophorectomy, 31 had salpingo-oophorectomy, which was unilateral in $21(62 \%)$ and bilateral in $10(29 \%)$ patients. Fourteen patients $(70 \%)$ with juvenile granulosa cell tumors had unilateral salpingo-oophorectomy and 6 $(30 \%)$ patients had bilateral salpingo-oophorectomy. Of the 34 adult granulosa cell tumors, 31 (91\%) were stage IA, and $3(9 \%)$ stage IC. Fifteen juvenile granulosa cell tumors were stage IA $(75 \%), 2(10 \%)$ stage IC, 1 (5\%) stage IIIB, and $2(10 \%)$ stage IIIC.

\section{Pathologic Findings}

The adult granulosa cell tumors had a median diameter of $11 \mathrm{~cm}$ (IQR $=6-17 \mathrm{~cm})$. The external surface was smooth and lobulated. The cut surfaces were described as solid or cystic, displaying a variegated appearance ranging from yellowish to gray with foci of hemorrhage and necrosis. Histologically, the tumors were densely cellular and showed uniform cells closely packed with regular and relatively bland nuclei. Twenty-one (62\%) tumors had a diffuse pattern, $6(17 \%)$ were trabecular, $4(12 \%)$ microfollicular, and $3(9 \%)$ appeared watered silk. Six tumors presented a different 
sex-cord component (thecoma, luteinized thecoma, Sertoli-Leydig, and sex-cord tumor with annular tubules). Mitotic count varied from 4 to 14/10 HPFs (IQR) (median = 5/10 HPFs).

The macroscopic features of juvenile granulosa cell tumors resembled those of the adult tumors, with a median diameter of $18 \mathrm{~cm}$ (IQR $=12-25 \mathrm{~cm})$. Microscopically, they showed confluent solid nodules of proliferating granulosa cells arranged in sheets or around irregular follicle-like spaces containing amphophilic secretory fluid. The nuclei did not show grooving, and were larger and more hyperchromatic than in the adult tumors. Three tumors presented a separate sex-cord component (Sertoli, Sertoli-Leydig). Mitotic count varied from 6 to $21 / 10 \mathrm{HPFs}$ (IQR) (median =12/10 HPFs).

\section{Follow-up and Survival}

Follow-up, ranging from 2 to 26 years (median $=9$ years), was available in 29 of 34 adult granulosa cell tumors, and in 13 of 20 juvenile granulosa cell tumors. Of the 29 patients with adult granulosa cell tumors, 12 (41\%) developed metastases, 1 (3\%) who had a stage IA tumor died of acute myocardial infarction, and $16(56 \%)$ patients were alive without evidence of disease. None was known to have died of tumor. Of the 13 patients with juvenile granulosa cell tumors and follow-up available, 3 (23\%) developed metastases and died of tumor 2 to 6 months later ( 1 stage IA, 1 stage IIIB, and 1 stage IIIC), and the remaining $10(77 \%)$ patients are alive without evidence of disease.

All patients were stratified into recurrent vs non-recurrent groups and no statistical differences were observed when compared by age at diagnosis, tumor size, tumor stage, histologic type, presence of a separate sex-cord component, and mitotic index.

Patients with juvenile granulosa cell tumors had a worse overall survival than those with adult granulosa cell tumors $(P=0.034)$; however, no differences in disease-free survival were found between the two groups. Moreover, in the former patients recurrence itself was a powerful predictor of prognosis $(P=0.000)$, and its significance was maintained even in stage $1 \mathrm{~A}$ cases $(P=0.025)$.

\section{FOXL2 Mutations and mRNA Expression}

Direct sequencing analysis showed that FOXL2 (C402G) missense mutation was present in 19/27 (70\%) adult type tumors while no mutation was encountered in any of the juvenile granulosa cell tumors (0/18). Moreover, we found no correlation between the presence of FOXL2 mutation and the clinicopathologic variables studied except for the presence of a separate sex-cord component, which was more frequent in the subgroup of wild-type adult granulosa cell tumors than in the mutated group $(P=0.031)$.
We then investigated whether FOXL2 mutation influenced the mRNA expression level of the gene. When compared with normal ovarian tissue of agepaired controls (median $=14.2 ; \quad$ IQR $=12.2-72.1$; $P=0.024$ ) and juvenile granulosa cell tumors (median $=2.34 ;$ IQR $=0.7-12.4 ; P=0.032$ ), all adult granulosa cell tumors overexpressed FOXL2 mRNA. Furthermore, we observed that tumors harboring the mutation tended to have a higher FOXL2 mRNA expression (median $=19.66 ; \mathrm{IQR}=2.3-39.9)$ than those with wild-type FOXL2 (median=5.07; $\mathrm{IQR}=1.5-83.1)$, although the difference was not significant $(P=\mathrm{ns})$ (Figure 1a).

\section{FOXL2 Mutation and mRNA Expression Influence Disease-Free Survival and Overall Survival}

When patients with adult granulosa cell tumors were stratified regarding their mutation status, we observed that patients with tumors harboring the FOXL2 (C402G) mutation had a worse disease-free survival than those with the wild-type gene $(P=0.046)$ (Figure 1b), while the overall survival was not affected by mutation status $(P=\mathrm{ns})$.

Once we found that mutated adult granulosa cell tumors had a higher expression of FOXL2 mRNA than unmutated cases, we explored whether gene expression may have also an impact on prognosis. Using $72 \mathrm{RU}$ as a cutpoint corresponding to the 75 th percentile of the FOXL2 mRNA expression in adult granulosa cell tumors, we found that patients with a higher FOXL2 mRNA expression had a worse disease-free survival than those with lower levels $(P=0.01)$ (Figure 1c). On the other hand, when patients were stratified by mRNA FOXL2 expression, we observed no differences in overall survival.

In contrast to the adult type, juvenile granulosa cell tumors with higher FOXL2 mRNA expression (cutoff value =2RU) had a worse disease-free survival $(P=0.039$; data not shown) and overall survival $(P=0.039)$ than those with lower expression (Figure 1d).

\section{Immunostaining for FOXL2 Correlates with mRNA Expression}

We stained 49 cases of granulosa cell tumors (30 adult type and 19 juvenile type) with FOXL2. In each tumor, immunostaining was homogeneous among the tumor cells. FOXL2 was expressed in 23 out of 30 of adult granulosa cell tumors and in 14 of 19 juvenile granulosa cell tumors (Figure 2). In both types, we found that immunohistochemical intensity varied among the groups according to mRNA FOXL2 expression $(P=0.006)$ and that the expression had an increasing linear tendency $(P=0.000)$. Moreover, we also found that the mutated cases showed a stronger immunoreaction for FOXL2 protein $(P=0.026)$. 

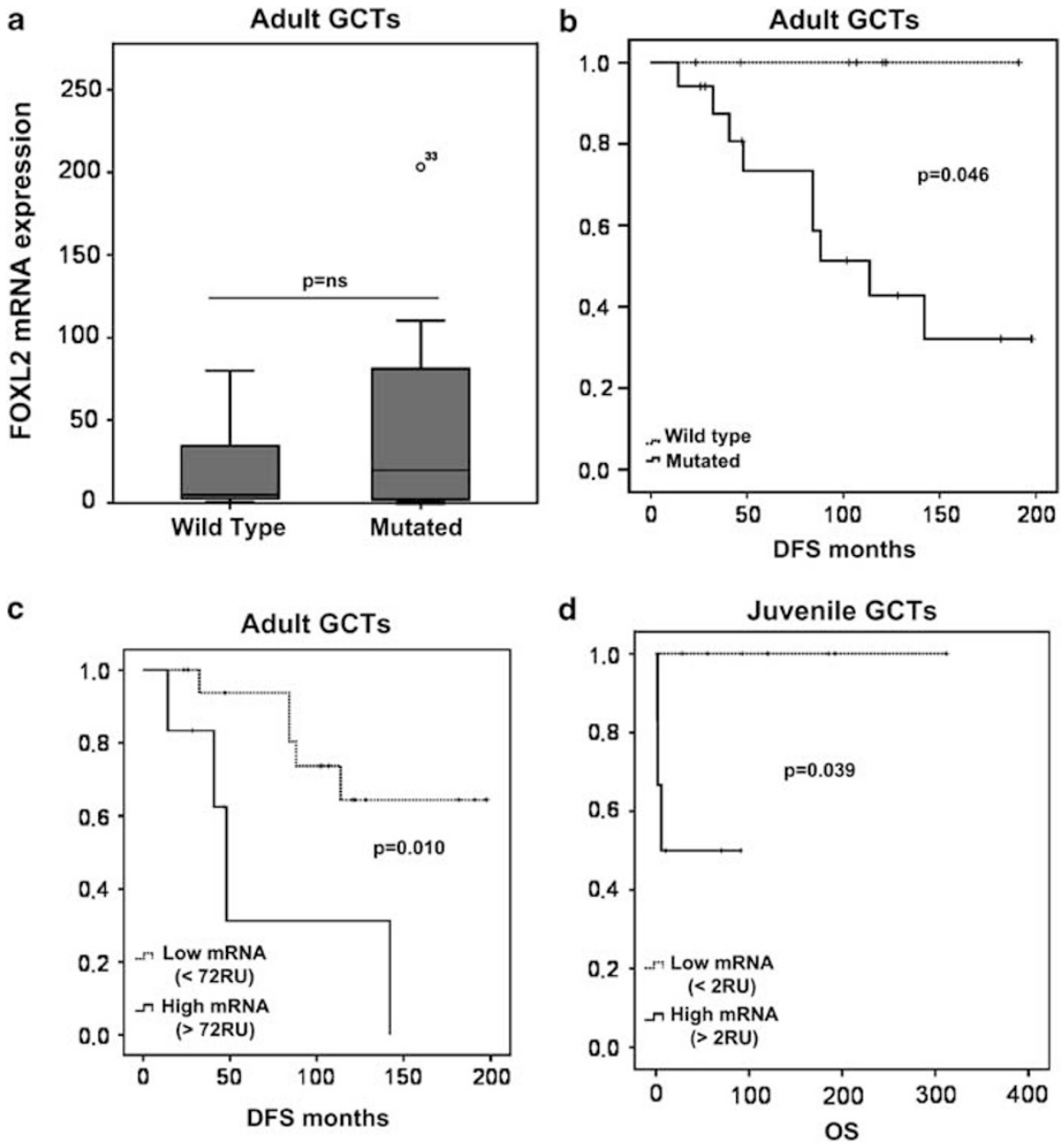

Figure 1 (a) Ovarian granulosa cell tumors, adult type with the FOXL2 (C402G) mutation tended to have a higher mRNA expression than tumors with wild-type FOXL2. (b) Patients with adult granulosa cell tumors and FOXL2 (C402G) mutation had a worse disease-free survival than patients with adult granulosa cell tumors without the mutation. (c) Patients with adult granulosa cell tumors and a higher FOXL2 mRNA expression ( $>72 \mathrm{RU}$ ) had a worse disease-free survival than those with lower expression. (d) Patients with juvenile granulosa cell tumors and a higher FOXL2 mRNA expression ( $>2 \mathrm{RU}$ ) had a worse overall survival than those with lower FOXL2 mRNA expression.

In adult granulosa cell tumors, no correlation was found between FOXL2 immunoreaction and overall survival or disease-free survival. Conversely, in juvenile granulosa cell tumors, we observed that tumors with a stronger $(2+$ and $3+)$ immunoreaction had a worse overall survival and disease-free survival, than tumors exhibiting negative or weak immunostaining $(1+)(P=0.02)$.

\section{Discussion}

Granulosa cell tumors account for only $3-5 \%$ of all ovarian tumors and have been classified into adult and juvenile clinicopathologic types. ${ }^{1,19}$ The tumors may exhibit a wide variety of histological patterns, which challenge diagnosis; prognosis is uncertain and pathogenesis poorly understood.

Several studies have attempted to predict recurrence. Some assessed clinical parameters such as age at diagnosis, tumor size, surgical stage, serum tumor markers, tumor rupture during surgery, and adjuvant chemotherapy after the initial surgery. ${ }^{3,6,9,19-22}$ Others analyzed pathologic features such as cellular atypia, mitotic index, histologic subtype, presence of Call-Exner bodies, and tumor cell luteinization..$^{20,22}$ In our series, none of the clinical and pathologic features we analyzed correlated with outcome.

Some light has been recently thrown on the pathogenesis of the adult granulosa cell tumors. Using RNA sequencing, Shah et $a l^{10}$ reported the identification of a likely 'driver' point mutation (C402G) of the FOXL2 gene-localized within the forkhead domain-in adult type granulosa cell tumors. However, little is known about the effect of this mutation in the function of the FOXL2 protein.

In our series, we encountered the FOXL2 (C402G) mutation in the majority of the adult granulosa cell tumors but in none of the juvenile cases. Interestingly, we found that cases with a different sex-cord component were more likely to be wild-type for the 
FOXL2 gene. It has been reported that patients with adult granulosa cell tumors containing a nongranulosa sex-cord component are associated with better disease-free survival. ${ }^{22}$ Although we could not find any survival differences between tumors with and without non-granulosa sex-cord component, our findings suggest, together with those in the literature, that adult granulosa cell tumors with a different sex-cord component may represent a distinct clinicopathologic form with more favorable prognosis.

Physiologically, FOXL2 is required for normal ovarian development and is mainly expressed in undifferentiated granulosa cells. Knockout mice present a blockage in ovarian development secondary to failure in granulosa cell differentiation. ${ }^{14,15}$ It has been recently reported that wild-type FOXL2 and its mutant may have differential regulatory activities of the apoptosis. According to Kim et al, ${ }^{17}$ FOXL2 mutant induces a lower number of apoptotic cells due to deregulation of the caspase activation. In this context, we reported for the first time that FOXL2 gene mutation may also have a bad prognostic impact in vivo.
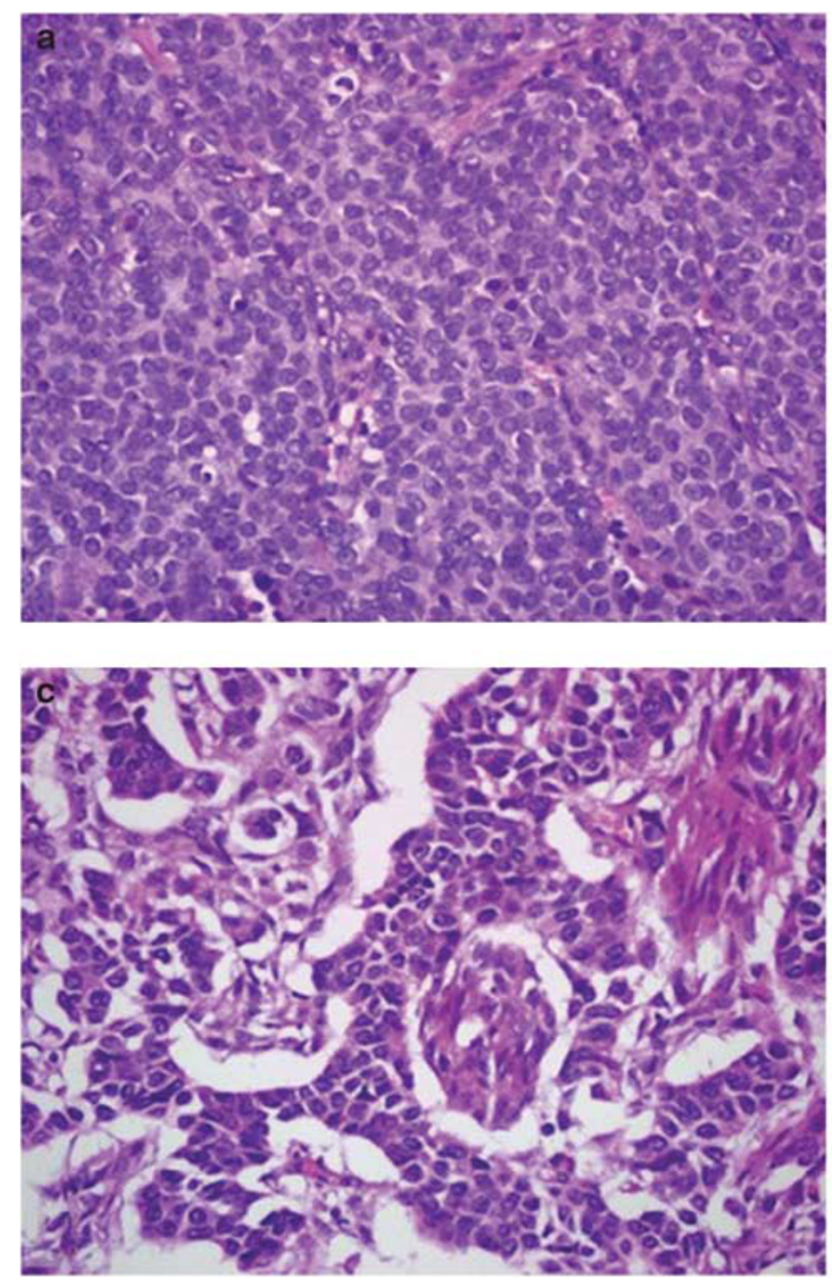

We examined FOXL2 mRNA expression in both adult and juvenile granulosa cell tumors. Our findings differ from those reported recently by Jamieson et al, ${ }^{16}$ who found that levels were similar in all cases and controls studied, irrespective of their adult or juvenile nature. In our series, both tumor types expressed higher levels of FOXL2 mRNA than normal ovaries, especially granulosa cell tumors. We also found for the first time that FOXL2 mRNA expression has a prognostic impact, not only in adult type tumors, but also in juvenile neoplasms. In our study, patients with adult granulosa cell tumors and a high mRNA FOXL2 expression had a worse disease-free survival than those with lower expression. In contrast, patients with juvenile granulosa cell tumors and higher FOXL2 mRNA expression had a worse disease-free survival and overall survival.

We then analyzed the immunohistochemical expression of FOXL2 in the same series of tumors, in order to evaluate its potential use as a diagnostic or prognostic surrogate marker. We observed that in both adult and juvenile granulosa cell tumors, there
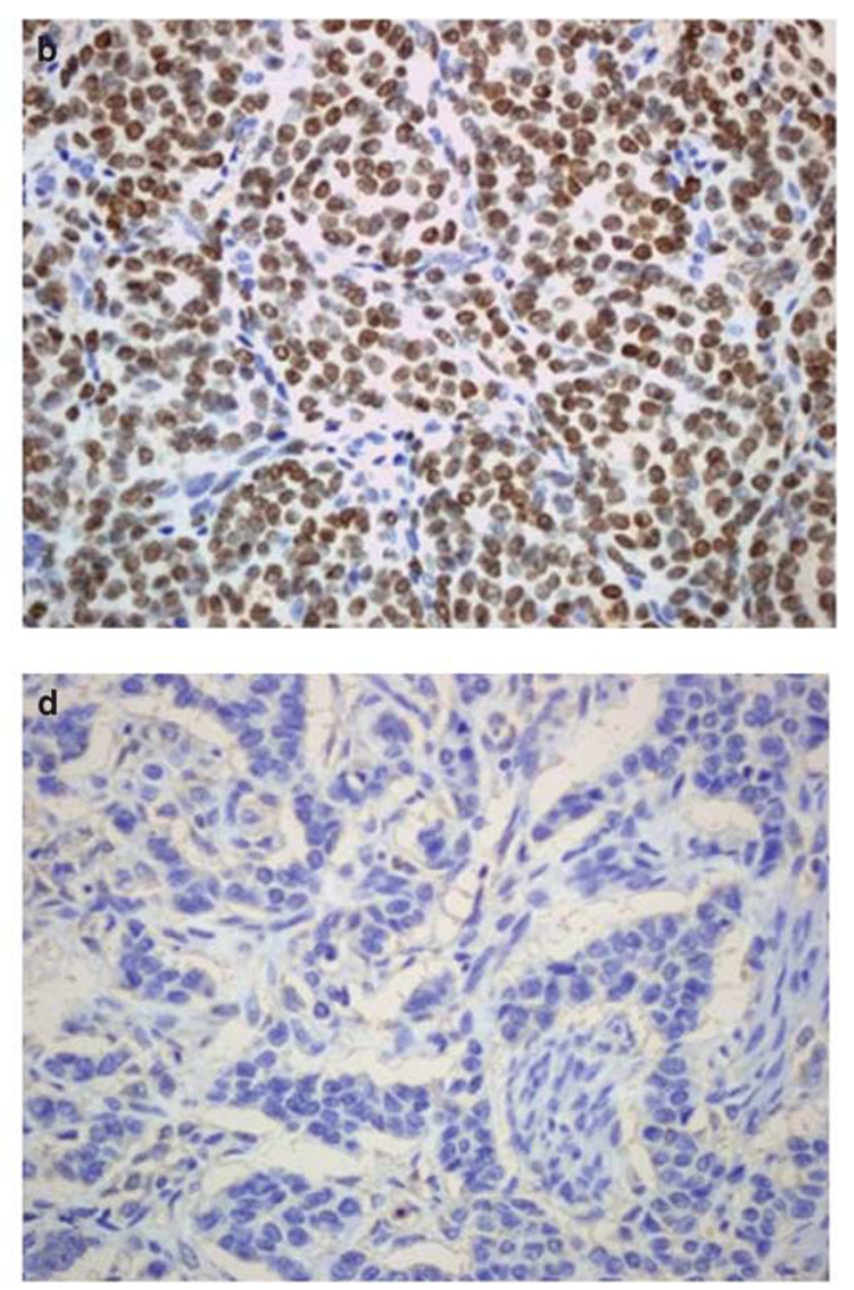

Figure 2 (a-d) Cases of ovarian granulosa cell tumors, adult type, showing strongly positive (b) and negative (d) immunoreaction for FOXL2. (e-h) Cases of ovarian granulosa cell tumors, juvenile type, showing weakly positive (f) and negative (h) immunoreaction for FOXL2. 

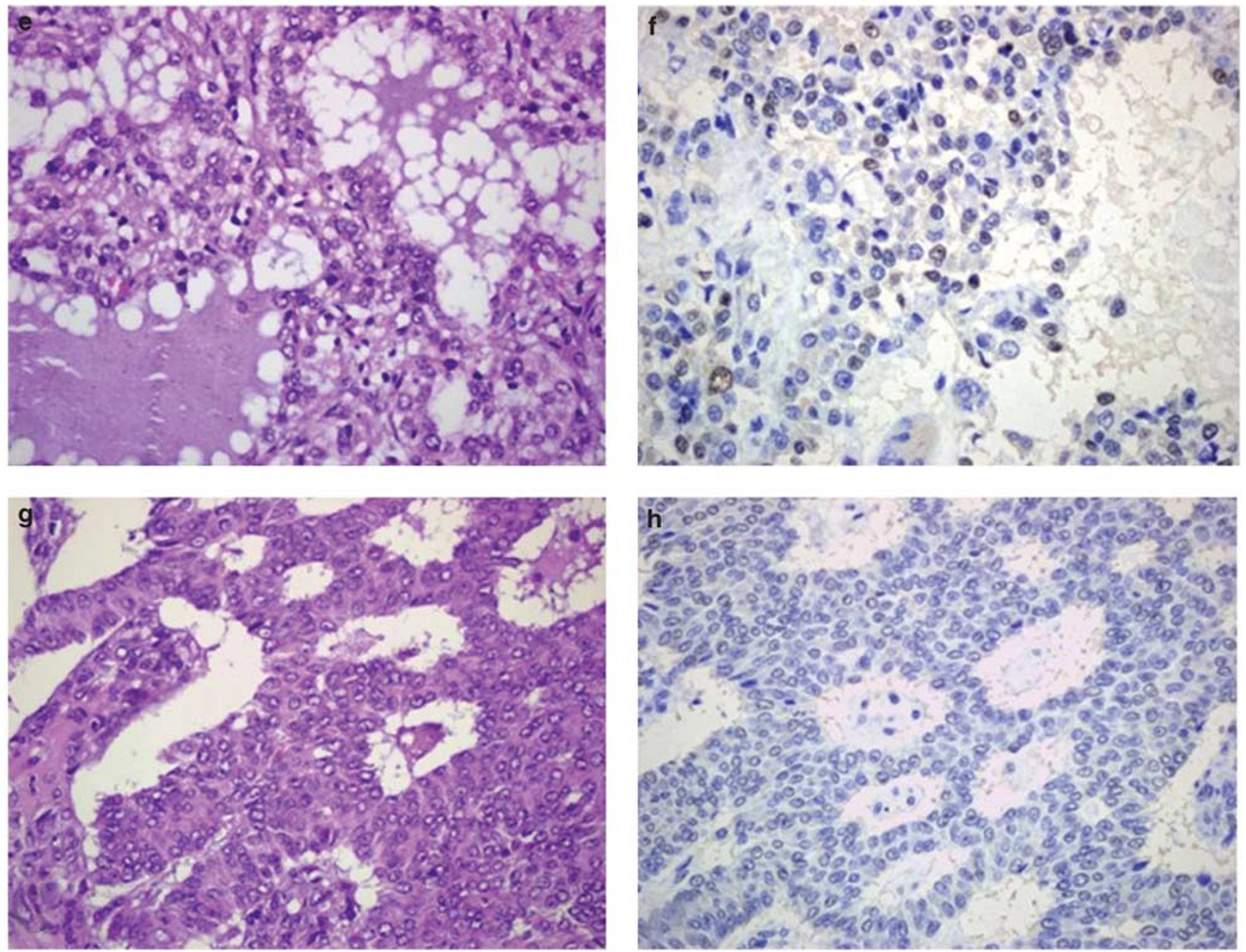

Figure 2 Continued.

was a linear correlation between mRNA and immunohistochemical FOXL2 expression. Nevertheless, the prognostic significance of the protein expression was only maintained in juvenile tumors.

In summary, we have demonstrated that FOXL2 mutation has not only a diagnostic value in adult granulosa cell tumors but also carries prognostic significance. We also believe that even if FOXL2 mutation may only have a pathogenetic role in adult granulosa cell tumors, FOXL2 expression also influences the biologic behavior of both juvenile and adult granulosa cell tumors and thus may be clinically relevant.

\section{Acknowledgement}

This work was supported by Grant RTICC RD06/ 0020/0015, Department of Health, Spain.

\section{Disclosure/conflict of interest}

The authors declare no conflict of interest.

\section{References}

1 Tavassoli FA, Mooney E, Gersell DJ, et al. Sex cordstromal tumors. In: Tavassoli FA, Devilee P (eds). World Health Organization Classification of Tumors Pathology and Genetics of Tumors of the Breast and Female Genital Organs. IARC Press: Lyon, 2003, pp 146-149.

2 Scully RE, Young RH, Clement PB. Tumors of the Ovary, Maldeveloped Gonads, Fallopian Tube, and Broad Ligament. Sex cord stromal tumors. Atlas of Tumor Pathology Fascicle 23, Armed Forces Institute of Pathology: Washington DC, 1998, pp 169-225.

3 Bjorkholm E, Silfversward C. Prognostic factors in granulosa-cell tumors. Gynecol Oncol 1981;11:261-274.

4 Calaminus G, Wessalowski R, Harms D, et al. Juvenile granulosa cell tumors of the ovary in children and adolescents: results from 33 patients registered in a prospective cooperative study. Gynecol Oncol 1997;65:447-452.

5 Lack EE, Perez-Atayde AR, Murthy AS, et al. Granulosa theca cell tumors in premenarchal girls: a clinical and pathologic study of ten cases. Cancer 1981;48:1846-1854.

6 Stenwig JT, Hazekamp JT, Beecham JB. Granulosa cell tumors of the ovary. A clinicopathological study of 118 
cases with long-term follow-up. Gynecol Oncol 1979;7: 136-152.

7 Young RH, Dickersin GR, Scully RE. Juvenile granulosa cell tumor of the ovary. A clinicopathological analysis of 125 cases. Am J Surg Pathol 1984;8: $575-596$.

8 Zaloudek C, Norris HJ. Granulosa tumors of the ovary in children: a clinical and pathologic study of 32 cases. Am J Surg Pathol 1982;6:503-512.

9 Fox H, Agrawal K, Langley FA. A clinicopathologic study of 92 cases of granulosa cell tumor of the ovary with special reference to the factors influencing prognosis. Cancer 1975;35:231-241.

10 Shah SP, Kobel M, Senz J, et al. Mutation of FOXL2 in granulosa-cell tumors of the ovary. $\mathrm{N}$ Engl J Med 2009;360:2719-2729.

11 Cocquet J, Pailhoux E, Jaubert F, et al. Evolution and expression of FOXL2. J Med Genet 2002;39: 916-921.

12 Schmidt D, Ovitt CE, Anlag K, et al. The murine winged-helix transcription factor Foxl2 is required for granulosa cell differentiation and ovary maintenance. Development 2004;131:933-942.

13 Lee K, Pisarska MD, Ko JJ, et al. Transcriptional factor FOXL2 interacts with DP103 and induces apoptosis. Biochem Biophys Res Commun 2005;336: 876-881.

14 Pisarska MD, Bae J, Klein C, et al. Forkhead 12 is expressed in the ovary and represses the promoter activity of the steroidogenic acute regulatory gene. Endocrinology 2004;145:3424-3433.

15 Uda M, Ottolenghi C, Crisponi L, et al. Foxl2 disruption causes mouse ovarian failure by pervasive blockage of follicle development. Hum Mol Genet 2004;13:1171-1181.

16 Jamieson S, Butzow R, Andersson N, et al. The FOXL2 C134W mutation is characteristic of adult granulosa cell tumors of the ovary. Mod Pathol 2010;23: 1477-1485.

17 Kim JH, Yoon S, Park M, et al. Differential apoptotic activities of wild-type FOXL2 and the adult-type granulosa cell tumor-associated mutant FOXL2 (C134W). Oncogene 2011;30:1653-1663.

18 Kononen J, Bubendorf L, Kallioniemi A, et al. Tissue microarrays for high-throughput molecular profiling of tumor specimens. Nat Med 1998;4:844-847.

19 Schumer ST, Cannistra SA. Granulosa cell tumor of the ovary. J Clin Oncol 2003;21:1180-1189.

20 Kusamura S, Derchain S, Alvarenga M, et al. Expression of p53, c-erbB-2, Ki-67, and CD34 in granulosa cell tumor of the ovary. Int J Gynecol Cancer 2003;13:450-457.

21 Malmstrom H, Hogberg T, Risberg B, et al. Granulosa cell tumors of the ovary: prognostic factors and outcome. Gynecol Oncol 1994;52:50-55.

22 Nosov V, Silva I, Tavassoli F, et al. Predictors of recurrence of ovarian granulosa cell tumors. Int J Gynecol Cancer 2009;19:628-633. 